\title{
BMJ Open Designing and psychometric evaluation of Stretching Exercise Influencing Scale (SEIS)
}

\author{
Mohammad Hossien Delshad, ${ }^{1}$ Sedigheh Sadat Tavafian, ${ }^{2}$ \\ Anoshirvan Kazemnejad ${ }^{3}$
}

To cite: Delshad MH, Tavafian SS, Kazemnejad A. Designing and psychometric evaluation of Stretching Exercise Influencing Scale (SEIS). BMJ Open 2019;9:e026565. doi:10.1136/ bmjopen-2018-026565

- Prepublication history for this paper is available online. To view these files, please visit the journal online (http://dx.doi org/10.1136/bmjopen-2018026565).

Received 14 September 2018 Revised 14 March 2019 Accepted 19 March 2019

D Check for updates

(C) Author(s) (or their employer(s)) 2019. Re-use permitted under CC BY-NC. No commercial re-use. See rights and permissions. Published by BMJ.

${ }^{1} \mathrm{PhD}$ candidate of Department of Health Education and Health Promotion, Faculty of Medical Sciences, Tarbiat Modares University, Tehran, Iran. ${ }^{2}$ Department of Health Education and Health Promotion, Faculty of Medical Sciences, Tarbiat Modares University, Tehran, Iran. ${ }^{3}$ Department of Biostatistics, Faculty of Medical Sciences, Tarbiat Modares University, Tehran, Iran.

Correspondence to Professor Sedigheh

Sadat Tavafian;

tavafian@modares.ac.ir

\section{ABSTRACT}

Objective The lack of reliable and valid tools for assessing the factors that influence stretching exercises (SEs) among Iranian office employees is obvious. This study aimed to design and evaluate psychometric properties of this instrument.

Design Cross-sectional study of psychometric properties. Setting Data were gathered from May to September 2017.

Participants Participants were 420 office employees who were working in 10 health centres affiliated to the Shahid Beheshti University of Medical Sciences in Tehran, Iran.

Primary outcome measures The instrument was designed on the basis of the constructs of the health promotion model (HPM) and extant literature. Exploratory factor analysis (EFA), Cronbach's $\alpha$ and intraclass correlation coefficient (ICC) were employed to check the scale's psychometric properties.

Results In total, 420 questionnaires were completed. The mean age of the office employees was $37.1 \pm 8.03$ years. Among the 86 items, 77 items had significant item-to-total correlations $(p<0.05)$. The results showed good internal consistency and reliability for the whole questionnaire and each domain. EFA results confirmed $53.32 \%$ of the total variance of the items yielded in 11 subscales. The ICC was acceptable $(0.78,95 \% \mathrm{Cl} 0.70$ to 0.88$)$.

Conclusions The Stretching Exercise Influencing Scale (SEIS) can be a reliable and valid instrument for measuring the factors that influence SEs among office employees. Trial registration IRCT20160824295512N1

\section{INTRODUCTION}

Musculoskeletal disorders (MSDs) are often correlated with ergonomic risk factors and also socioeconomic characteristics of workers. ${ }^{1}$ Globally, biopsychosocial factors of the workplace affect the majority of the world's population who spend most of their waking hours in their workplace. ${ }^{2}$ One of the most important risk factors for computer users in the work sites is prolonged sitting without doing stretching exercises (SEs). ${ }^{3}$ Work-related MSDs (WMSDs) are one of the prevalent health problems at the work sites. ${ }^{4}$ Repetitive motions, excessive inactivity or prolonged sitting as well as psychological stresses

\section{Strengths and limitations of this study}

The Stretching Exercise Influencing Scale (SEIS) could be a validated and reliable instrument to determine the factors that influence stretching exercises among 420 employees who work with computers in Shahid Beheshti University of Medical Sciences, Tehran, Iran

- In this study, the selected convenience sample from just one university may not reflect all Iranian employee population profiles, so the generalisation of the present results is limited.

- However performing additional studies with computer users from other organisations and with different population profiles, and social, educational and cultural demographics should be accomplished to confirm the results.

- It is also suggested that the SEIS should be justified to other languages and cultures so that it could be applied in other countries.

have been associated with WMSDs among computer operators. ${ }^{5}$ SEs can lead to permanent lengthening of ligaments and tendons ${ }^{6}$ and it seems to have an impact on decreasing WMSDs especially among computer operators. $^{78}$

In a previous study it was argued that inactivity and not doing SEs were prevalent among Iranian computer operators. ${ }^{9}$ The health promotion model (HPM) is one of the comprehensive models that determine the influencing factors that affect health promoting behaviours especially at work sites. This model describes factors like perceived barrier/benefit to action, perceived self-efficacy, interpersonal influences, commitment to a plan of action, immediate competing demands/preferencesand situational influence on health behaviour-for instance SEsin the context of the work site. ${ }^{10}$ However, a previous study ${ }^{11}$ showed that other factors such as stimulus control, counterconditioning and self-regulation were influencing exercise behaviours. It has been documented 
that not doing exercise among Iranian office workers was prevalent and, on the other hand, there was no valid instrument to measure real needs of Iranian computer users based on HPM constructs to assess the causes for not doing Stretching Exercise (SE). A previous study revealed that the weight of the influencing factors on stretching training can vary depending on the cultural context. ${ }^{12}$ Therefore, developing a reliable instrument for assessing factors influencing SEs is essential to understanding and addressing the interventional programme to promote SE. In this context, the objective of this research was to develop and validate a culturally based instrument to evaluate factors influencing SE among a sample of Iranian computer users.

\section{OBJECTIVES}

The objective of this research was to develop and validate a culturally HPM-based instrument to evaluate SE influencing factors among a sample of Iranian computer users.

\section{METHODS}

This cross-sectional study was part of a $\mathrm{PhD}$ thesis in Tarbiat Modares University, Tehran, Iran. All the participants signed an informed written consent form to participate in this study.

For this study, first of all, a questionnaire including 86 items pertaining to the mentioned constructs of HPMin the context of WMSDs and based on the existing evidences-was designed. The validity of the instrument was determined by a sample of 420 office employees who were working at health centres and were eligible due to the inclusion/exclusion criteria. The inclusion criteria were having no disability or illnesses to prevent SEs and signing the written consent form. So, those suffering from any defect or illness interfering with SE were excluded from the study. Both quantitative and qualitative approaches were taken for face validity of the questionnaire. In the qualitative approach, 30 office employees assessed each item of the questionnaire for 'ambiguity', 'relevancy' and 'difficulty'. In this process, three items needed to be improved.

For the quantitative approach, the same office employees were asked to determine the importance of each item through a 5-point Likert Scale. In this way the impact score for each item was calculated. As the impact score of 1.5 or above was satisfactory, all the items were approved for the instrument.

Content validity was done by both qualitative and quantitative methods. For the qualitative method an expert panel consisting of 15 specialists, including 6 health education specialists, 2 psychologists, 1 psychometric specialist, 1 physiotherapist, 1 neurological pain manager, 1 orthopaedic specialist, 1 physical medicine expert and 1 nurse with experience on pain management, checked all the survey items. These experts inserted their recommendations into the questionnaire. Moreover, they also

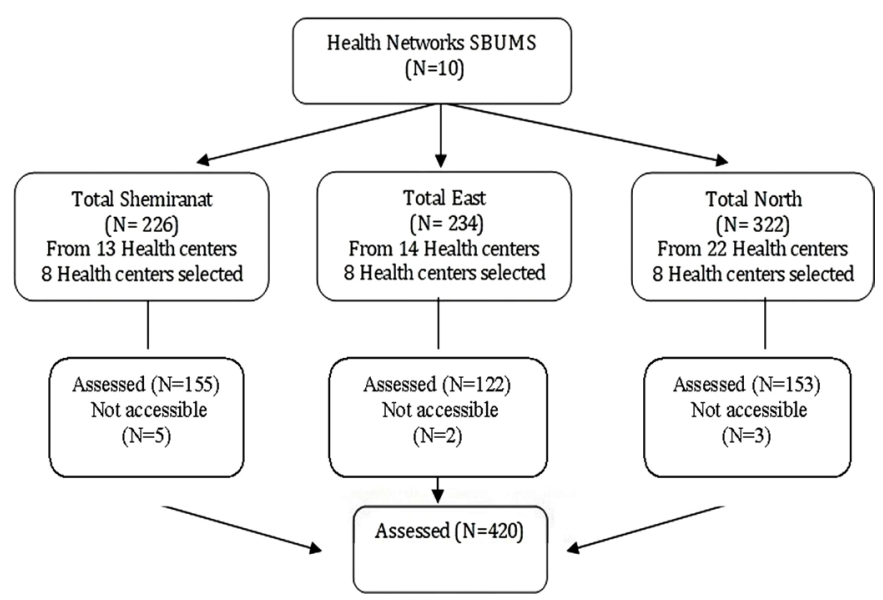

Figure 1 Flow of the procedure for sampling office employees. Shahid Beheshti University of Medical Sciences (SBUMS).

evaluated the questionnaire for 'grammar', 'wording', 'item allocation' and 'scaling' indices. This expert panel was asked to comment on item relevance, item comprehensiveness and any confusing meaning.

For quantitative content validity, the Content Validity Ratio (CVR) and Content Validity Index (CVI) were used. The necessity of an item was assessed through CVR and items with a score $<0.4$ were deleted according to Harrington. ${ }^{13}$ The simplicity, relevance and clarity of the items were assessed through CVI and a value of 0.79 or above was considered satisfactory for each item.

According to a rule of five individuals for each item $(86 \times 5)$, a sample size of 385 computer users was estimated for exploratory factor analysis (EFA). However, for greater accuracy the sample size was increased to 420 individuals. ${ }^{14}$ Multistage cluster sampling was applied to select the sample for psychometric evaluation of the instrument. First, from 10 health networks of Shahid Beheshti University of Medical Sciences, the North, Shemiranat and East networks were selected. Then eight health centres were selected from each health network, and 150 computer users from each health centre in the North and Shemiranat networks and 120 office employees from the health centre in the East network were randomly selected. Figure 1 shows the sampling procedure.

The primary questionnaire included 19 demographic questions and 86 questions relevant to the 11 constructs of HPM and other evidences. Each construct included five to nine questions. The construct validity of the questionnaire was examined through EFA. Principal component analysis with varimax rotation was performed to extract the underlying factors. Factor loadings $\geq 0.5$ were considered appropriate. Eigenvalues $>1$ and Scree plots were used for determining the number of statements. The Kaiser-Meyer-Olkin (KMO) measure and Bartlett's test of sphericity $(\mathrm{p}<0.001)$ were used to assess the appropriateness of the sample size for factor analysis.

The excluded factors from the factor analysis were those that did not increase behaviour variance. Cronbach's 
Table 1 Demographic test-retest sample and EFA study

\begin{tabular}{|c|c|c|c|}
\hline \multirow[b]{2}{*}{ Variables } & \multirow[b]{2}{*}{ Levels } & \multirow{2}{*}{$\begin{array}{l}\text { Test-retest sample }(\mathrm{n}=30) \\
\mathrm{N}(\%)\end{array}$} & \multirow{2}{*}{$\begin{array}{l}\text { EFA sample }(n=420) \\
N(\%)\end{array}$} \\
\hline & & & \\
\hline \multirow[t]{3}{*}{ Age (years) } & $\leq 25$ & $1(3.3)$ & $26(6.2)$ \\
\hline & $31-35$ & $11(36.7)$ & $106(25.2)$ \\
\hline & $36-40$ & $4(13.3)$ & $78(18.6)$ \\
\hline \multirow[t]{3}{*}{ Marriage status } & Single & $9(30.0)$ & $120(28.6)$ \\
\hline & Married & $21(70.0)$ & $289(68.8)$ \\
\hline & Others & - & $11(2.6)$ \\
\hline \multirow[t]{2}{*}{ Education level } & Diploma and under diploma & - & - \\
\hline & Associate degree and undergraduate & 19 (63.3) & $303(71.11)$ \\
\hline \multirow{2}{*}{ Location of health centre } & East & $10(33.3)$ & $150(35.7)$ \\
\hline & Shemiranat & 10 (33.3) & $120(28.6)$ \\
\hline \multirow[t]{5}{*}{ Work experience (years) } & $<5$ & $6(20.0)$ & $157(37.4)$ \\
\hline & $5-10$ & $9(30.0)$ & $69(16.4)$ \\
\hline & $11-15$ & $5(16.7)$ & $71(16.9)$ \\
\hline & $16-20$ & $6(20.0)$ & $78(18.6)$ \\
\hline & $20.00+$ & $4(13.3)$ & $45(10.7)$ \\
\hline
\end{tabular}

EFA, exploratory factor analysis.

$\alpha$ coefficient values were used to assess the internal consistency of the Stretching Exercise Influencing Scale (SEIS). Intraclass correlation coefficient (ICC) was done with 30 computer users who completed the questionnaire twice at a 2-week interval. The acceptable value for ICC was considered 0.4 or above. Data analyses were undertaken using the Statistical Package for Social Sciences. The frequency/percentage and mean (SD) for analysing demographic variables were used.

\section{PATIENT AND PUBLIC INVOLVEMENT}

Patients and/or public were not involved in the designing and planning of the study.

\section{RESULTS}

In all, 420 office employees including 113 men (26.9\%) and 307 women $(73.1 \%)$ participated in the study. Table 1 shows the demographic characteristics of the participants. The KMO measure was 0.914 , which fell in the 'very good' category. Bartlett's test of sphericity was meaningful $(p<0.001)$ which indicates that the sample size was sufficient for EFA. Through EFA, from the primary 86 items, 9 items were not loaded on any factor and were removed. The initial analysis indicated an 11-factor structure with 77 items for the questionnaire with a total score between 77 and 293. All the remaining items were found to have significant item-to-total correlations $(\mathrm{p}<0.05)$. Table 2 shows the main factor analysis of the varimax rotation for the questionnaire. Table 3 shows all 11 factors and their reliability characteristics. All 11 factors had real commonalities (the subscales ranged between 0.73 and $0.89)$. Cronbach's $\alpha$ coefficient for SEIS was 0.84 with a satisfactory result.

Test-retest of the scale at a 2-week interval was done on 30 computer users. All computer users complied with that because all were working and available in the office after 2 weeks. The results of ICC indicated appropriate and acceptable stability (ICC $=0.78,95 \%$ CI 0.70 to 0.88 ). The SEIS showed well constructed reliability and validity.

\section{DISCUSSION}

This study developed and evaluated the psychometric properties of SEIS among a sample of Iranian computer users. The 11-factor structure of SEIS was consistent with the original constructs of HPM and other evidence-based constructs. This well-constructed 11-subscale instrument may be due to good items that were based on good literature review and good experience of researchers regarding not practising $\mathrm{SE}$ in workplaces in Iran. The large sample size $(n=420)$ of this study may result in good response for the designed instrument. 


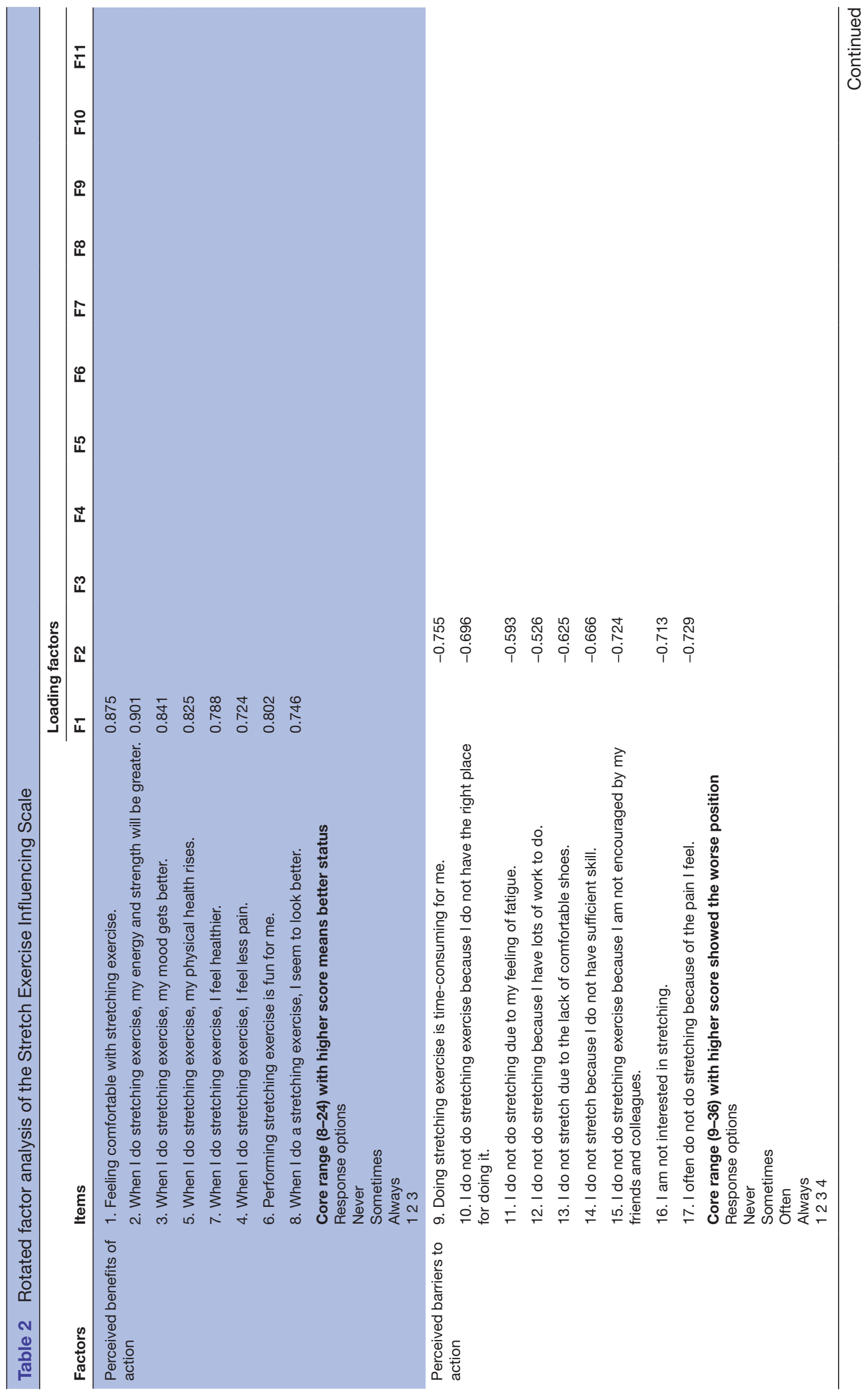

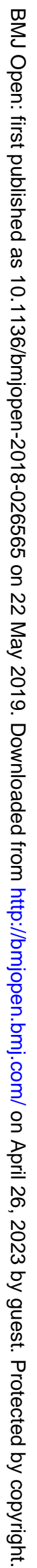




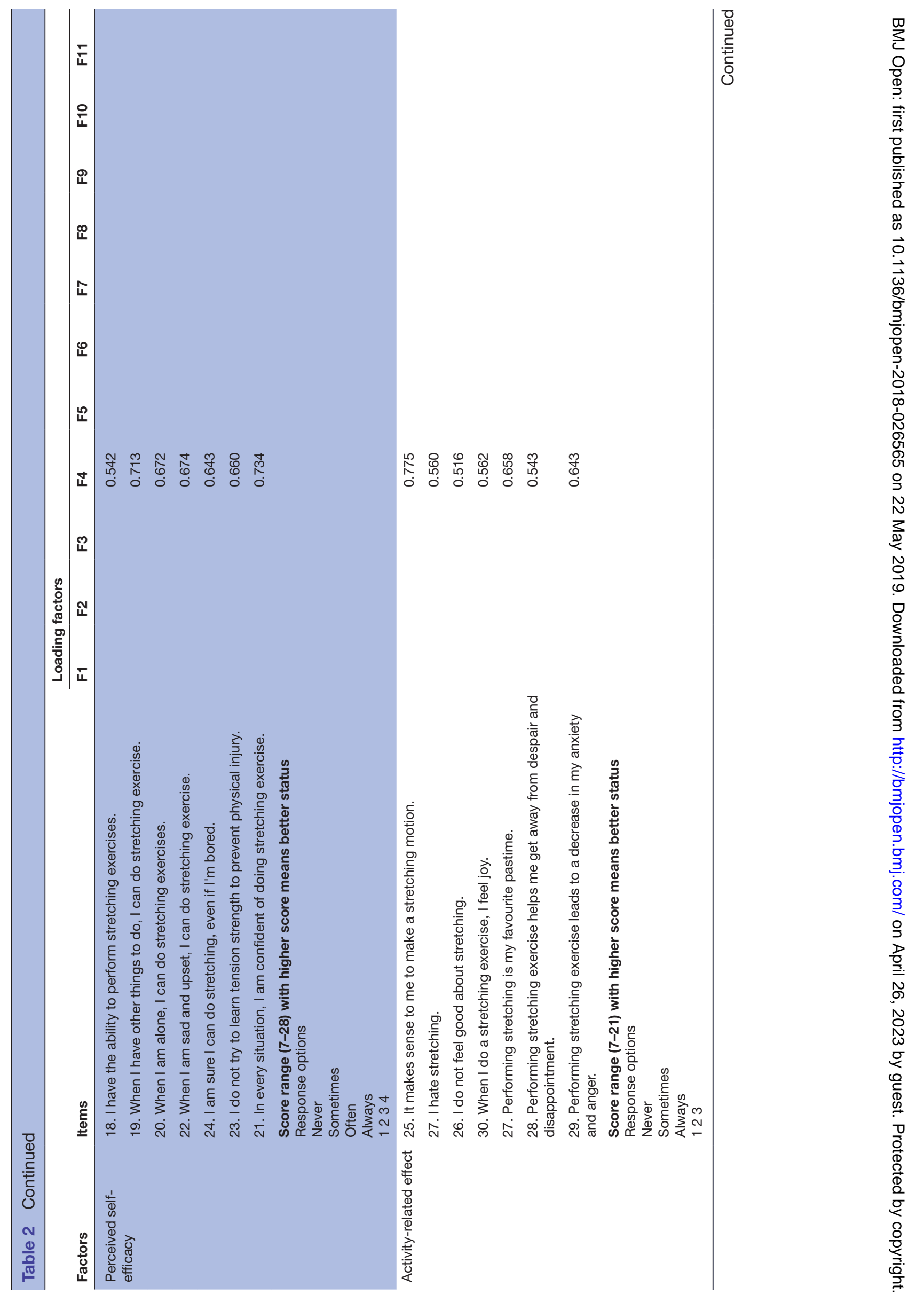




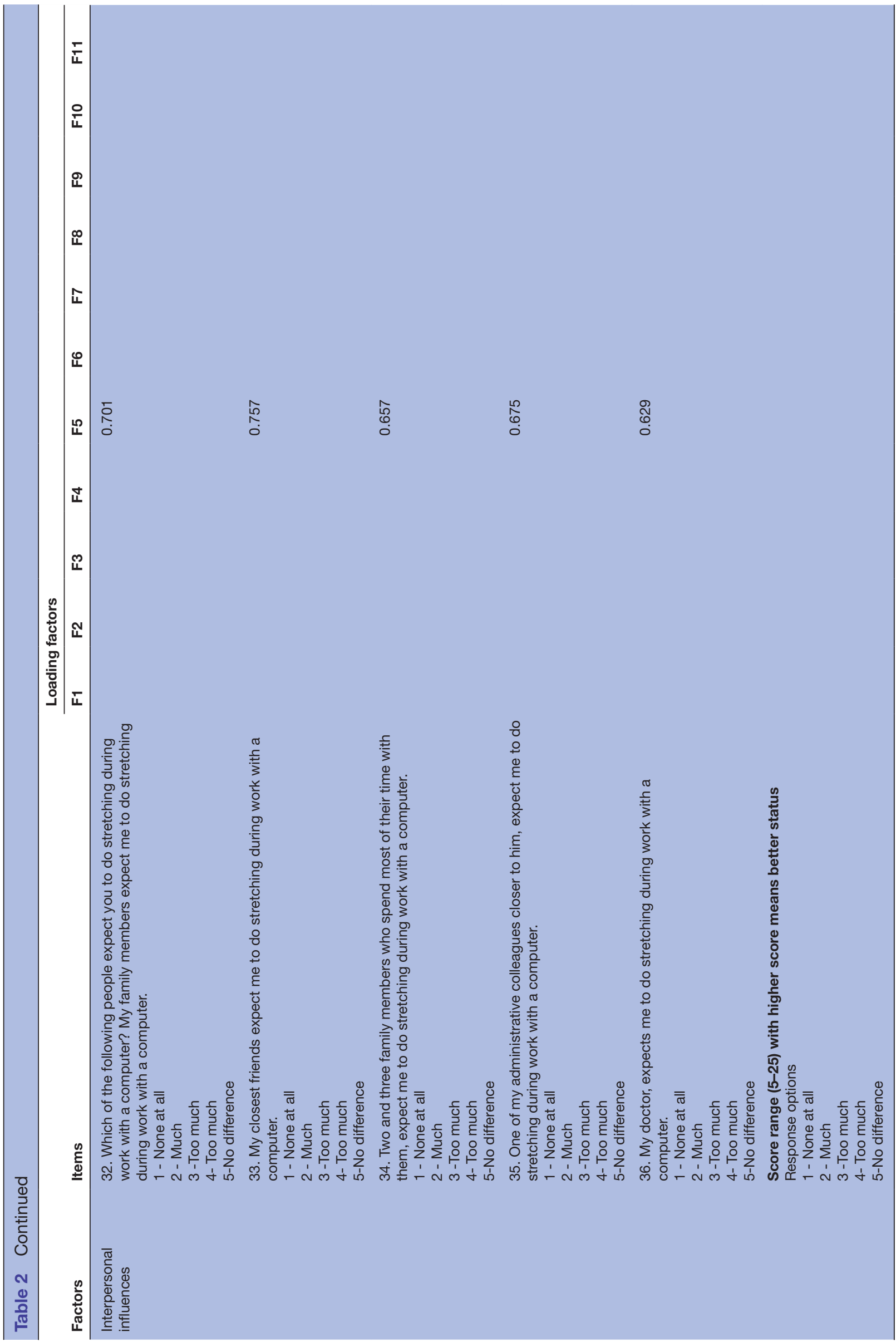




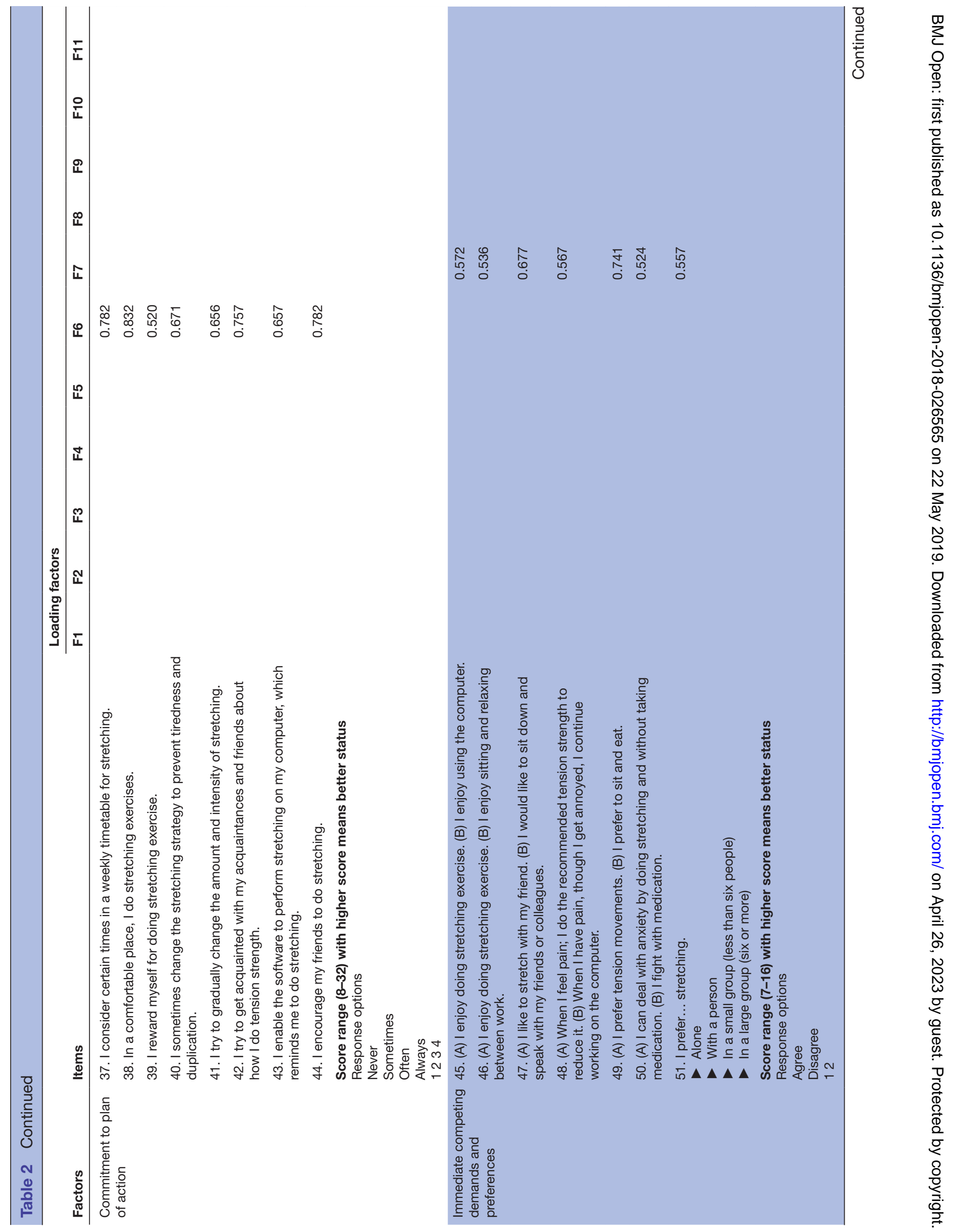




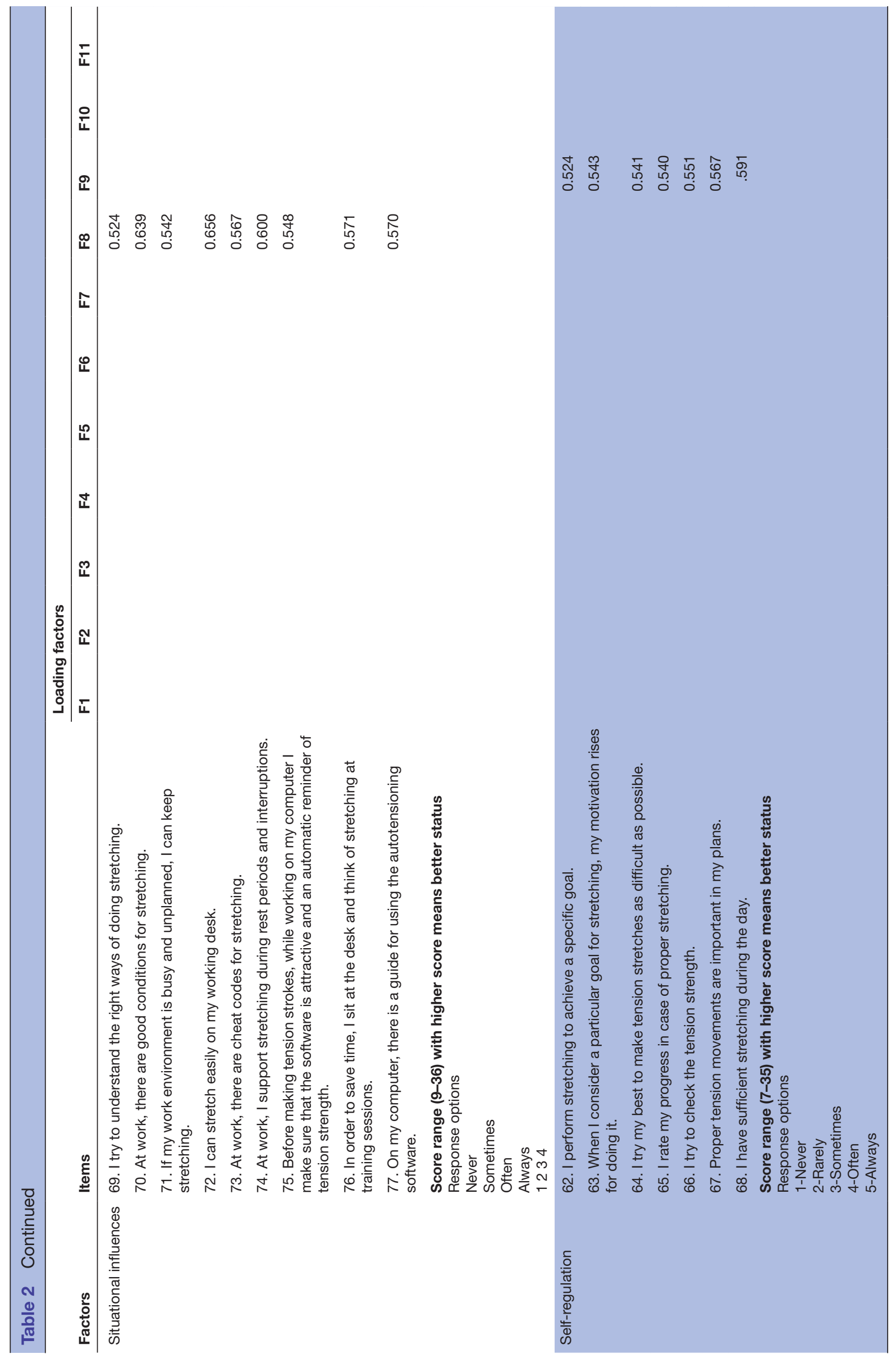

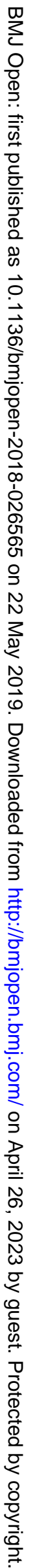




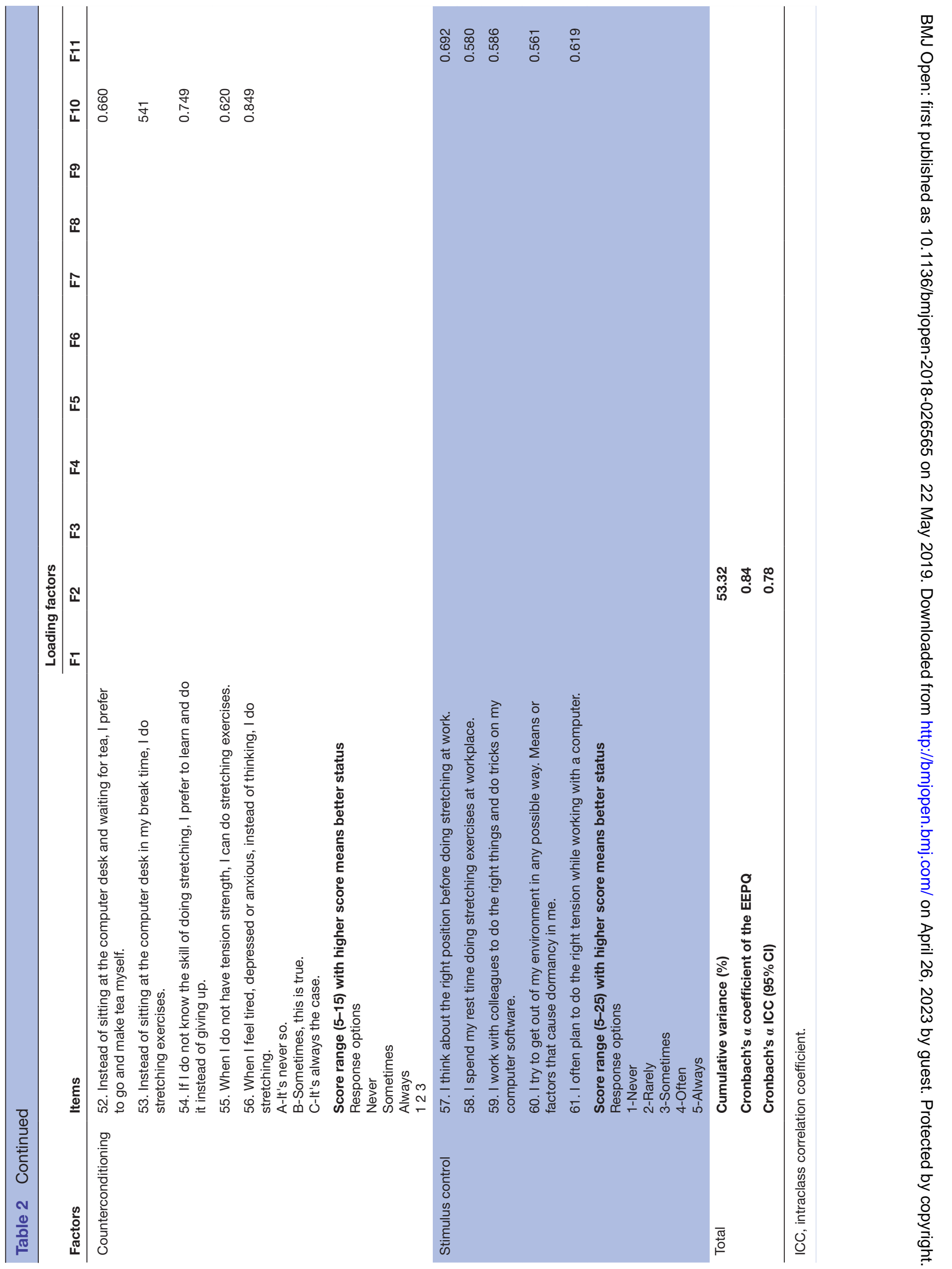


Table 3 Specifications of the developed Pender's model, changing the Stretching Exercise Influencing Scale in Iranian office employees $(n=420)$

\begin{tabular}{lllllll}
\hline & & & $\mathbf{R}$ & Explained & Cronbach's $\boldsymbol{\alpha}$ & ICC \\
\cline { 6 - 7 } Concepts & N of items & Mean (SD) & Eigenvalues & variance (\%) & coefficient & $\mathbf{( 9 5 \% ~ C l ) ~}$ \\
\hline Perceived benefits of action & 8 & $17.90(5.05)$ & 3.423 & 6.227 & 0.89 & 0.84 \\
Perceived barriers to action & 9 & $20.31(6.031)$ & 6.79 & 7.523 & 0.86 & 0.79 \\
Perceived self-efficacy & 7 & $17.15(3.71)$ & 0.557 & 7.583 & 0.89 & 0.88 \\
Activity-related effect & 7 & $16.27(2.45)$ & 1.311 & 4.371 & 0.87 & 0.85 \\
Interpersonal influences & 5 & $11.55(4.64)$ & 1.504 & 3.354 & 0.82 & 0.71 \\
Commitment to a plan of action & 8 & $16.82(4.28)$ & 1.61 & 7.771 & 0.85 & 0.74 \\
Immediate competing demands and & 7 & $11.70(2.80)$ & 1.813 & 3.656 & 0.74 & 0.71 \\
preferences & & & & & & 0.71 \\
Situational influences & 9 & $14.21(4.59)$ & 1.963 & 4.086 & 0.79 & 0.71 \\
Self-regulation & 7 & $19.71(4.98)$ & 1.013 & 2.432 & 0.89 & 0.87 \\
Counterconditioning & 5 & $12.41(2.53)$ & 1.908 & 3.126 & 0.84 & 0.74 \\
Stimulus control & 5 & $11.99(2.80)$ & 4.632 & 3.193 & 0.73 & 0.7 \\
Total & 77 & $14.30(3.7)$ & - & 53.32 & 0.84 & 0.78 \\
\hline
\end{tabular}

ICC, intraclass correlation coefficient.

The internal consistencies of SEIS' subscales were also similar to those demonstrated by other studies. ${ }^{9}{ }^{15} 16$ Furthermore, in this study, explanatory factor analysis showed that the factors of perceived barriers to action, perceived self-efficacy and commitment to plan of action had satisfactory loading and contributed to doing SE. These findings are in the line with that of another study which found that commitments to other preferences prevent individuals from doing exercises in the workplaces, while perceived adherence to plan caused home exercise motivation. ${ }^{17}$ Another study revealed that commitment to plan of action is a key concept of HPM that could influence behaviour. ${ }^{10}$ These evidences support the results of the present study with regards to the validity of SEIS. However, the current study relies on the fact that self-regulation, counterconditioning and stimulus control construct were satisfactorily loaded in the instrument which influences preferences. These findings are in line with other evidences that argue with the positive impacts of these factors on the construct of preferences. ${ }^{18}$

In SEIS, there was a positive relationship between perceived benefit and doing SE that is supported by the results from other studies. ${ }^{18-20}$ Moreover, in the present study, perceived barrier and self-efficacy levels were found to be effective for SE. This result is consistent with the confirmatory factor analysis of HPM in Robbins' study in which social support structures, perceived barriers and self-efficacy were fit and significantly correlated with physical activity. ${ }^{21}$ It is well known that the perceived barriers to action could demotivate individuals' behaviour, so it is most important. Similar to the present study, a previous study stated that self-efficacy in physical activity could overcome external and internal barriers. ${ }^{22}$ Sharma, in his study, reported that physical activity interventions need to be built on promoting self-efficacy. ${ }^{23}$

Previous evidence reported the satisfactory validity and reliability for self-efficacy in the exercise scale among older adults. ${ }^{24}$ In our study, the instrument jointly accounted for $53.32 \%$ of the total variance for doing SE, which is well above the earlier studies assessing the model without the three constructs. Furthermore, it was determined that the structure of the instrument consisting of 11 factors and 77 questions explained desirable variance for doing SE. Zheng's and Newman's studies showed 57\% and $71 \%$ of the variance in adherence to exercise, respectively, both of which are higher rates compared with our study. ${ }^{10} 13$ While our analysis suggested that the SE scale showed good reliability and strong internal consistency, Rivière's study ${ }^{25}$ showed poor-to-good reliability, credibility and concurrent validity.

This study designed and validated an SEIS among Iranian office employees. According to the findings, satisfactory psychometric properties for the instrument were achieved. This achievement regarding good factor recovery may be due to adequate sample size (420 individuals) in this study, although the limitation of small sample size has been mentioned in other study. ${ }^{26}$

WMSDs of different employees were not specifically the same ${ }^{27}$. WMSDs are a multidisciplinary problem and biopsychosocial demographic characteristics may affect it. ${ }^{28}{ }^{29}$ Moreover, no analysis was done to realise the differences between the subgroups in terms of marital status and educational level. In spite of these differences, a questionnaire with a good recovery factor could be obtained because of the general similarities between the reasons for not doing SE at the work site. 
The results of this study are not representative of the general population due to sampling from only one university and also because the majority of the participants was aged $\geq 41$ years. However, despite these probable limitations, the designed scale could determine the factors that may have an impact on doing SE among the target group.

\section{CONCLUSION}

The designed scale in the present study could determine the factors which may have an impact on doing SE among a sample of Iranian computer users. Therefore, this study could be a foundation for further investigations for confirming this instrument as a culturally appropriate tool for assessing factors that may influence SE behaviour.

Acknowledgements The authors thank the research deputy of Tarbiat Modares University for financial support.

Contributors MHD conducted the study and had full access to all of the data for analysis. Also, he confirmed the eligibility of the office workers for the study. He was also involved in drafting the article. SST and AK supervised the whole study and approved the final version of the manuscript.

Funding Tarbiat Modares University.

Competing interests None declared.

Patient consent for publication Obtained.

Ethics approval The ethics committee of Tarbiat Modares University has approved the study (IR.TMU.REC.1395.329).

Provenance and peer review Not commissioned; externally peer reviewed.

Data sharing statement № additional data are available.

Open access This is an open access article distributed in accordance with the Creative Commons Attribution Non Commercial (CC BY-NC 4.0) license, which permits others to distribute, remix, adapt, build upon this work non-commercially, and license their derivative works on different terms, provided the original work is properly cited, appropriate credit is given, any changes made indicated, and the use is non-commercial. See: http://creativecommons.org/licenses/by-nc/4.0/.

\section{REFERENCES}

1. Shariat A, Cleland JA, Danaee M, et al. Effects of stretching exercise training and ergonomic modifications on musculoskeletal discomforts of office workers: a randomized controlled trial. Braz $J$ Phys Ther 2018;22:144-53.

2. Batt ME. Physical activity interventions in the workplace: the rationale and future direction for workplace wellness. $\mathrm{Br} J$ Sports Med 2009;43:47-8.

3. Kim D, Cho M, Park Y, et al. Effect of an exercise program for posture correction on musculoskeletal pain. J Phys Ther Sci 2015;27:1791-4.

4. Mohammed M, Layth Naji F, Naji FL. Benefits of exercise training for computer-based staff: a meta analyses. International Journal of Kinesiology and Sports Science 2017;5:16-23.

5. Hadgraft NT, Brakenridge CL, LaMontagne AD, et al. Feasibility and acceptability of reducing workplace sitting time: a qualitative study with Australian office workers. BMC Public Health 2016;16:933.

6. Hensrud D. The Mayo Clinic Diet: RosettaBooks, 2017.

7. Robertson MM, Huang YH, Lee J. Improvements in musculoskeletal health and computing behaviors: Effects of a macroergonomics office workplace and training intervention. Appl Ergon 2017;62:182-96.
8. Daneshmandi $\mathrm{H}$, Choobineh $\mathrm{A}$, Ghaem $\mathrm{H}$, et al. Adverse effects of prolonged sitting behavior on the general health of office workers. $J$ Lifestyle Med 2017;7:69-75.

9. Abdi J, Eftekhar H, Mahmoodi M, et al. Physical activity status and position of governmental employees in changing stage based on the trans-theoretical model in Hamadan, Iran. Glob J Health Sci 2015;7:23.

10. Pender NJ, Murdaugh CL, Parsons MA. Health promotion in nursing practice, 2015.

11. Cardinal BJ. Construct validity of stages of change for exercise behavior. Am J Health Promot 1997;12:68-74.

12. Holzgreve F, Maltry L, Lampe J, et al. The office work and stretch training (OST) study: an individualized and standardized approach for reducing musculoskeletal disorders in office workers. J Occup Med Toxicol 2018;13:37.

13. Harrington D. Confirmatory factor analysis: Oxford University Press, 2009.

14. Hajizadeh E, Asghari M. Statistical methods and analyses in health and biosciences a research methodological approach. 395. Tehran: Jahade Daneshgahi Publications, 2011.

15. Zheng J, You LM, Lou TQ, et al. Development and psychometric evaluation of the Dialysis patient-perceived Exercise Benefits and Barriers Scale. Int J Nurs Stud 2010;47:166-80.

16. Sarallah S, Sadat TS, Jamshidi AR, et al. A multidisciplinary work-related low back Pain predictor questionnaire: psychometric evaluation of Iranian patient-care workers. Asian Spine J 2016;10:501-8

17. Newman-Beinart NA, Norton S, Dowling D, et al. The development and initial psychometric evaluation of a measure assessing adherence to prescribed exercise: the Exercise Adherence Rating Scale (EARS). Physiotherapy 2017;103:180-5.

18. Taymoori P, Niknami S, Berry T, et al. A school-based randomized controlled trial to improve physical activity among Iranian high school girls. Int J Behav Nutr Phys Act 2008;5:18.

19. Vahedian-Shahroodi M, Amin-Shokravi F. The Effect of theory-based educational intervention on promoting physical activites of employees in Khorasan Dairy Industeries Tarbiat modares, 2013.

20. Shin Y, Yun S, Pender NJ, et al. Test of the health promotion model as a causal model of commitment to a plan for exercise among Korean adults with chronic disease. Res Nurs Health 2005;28:117-25.

21. Robbins LB, Ling J, Wesolek SM, et al. Reliability and validity of the commitment to physical activity scale for adolescents. Am J Health Promot 2017;31:343-52.

22. Pirasteh A, Hidarnia A, Asghari A, et al. Development and validation of psychosocial determinants measures of physical activity among Iranian adolescent girls. BMC Public Health 2008;8:150.

23. Sharma M, Sargent L, Stacy R. Predictors of leisure-time physical activity among African American women. Am J Health Behav 2005;29:352-9.

24. Choi M, Ahn S, Jung D. Psychometric evaluation of the Korean Version of the Self-Efficacy for Exercise Scale for older adults. Geriatr Nurs 2015;36:301-5.

25. Rivière F, Widad FZ, Speyer E, et al. Reliability and validity of the French version of the global physical activity questionnaire. J Sport Health Sci 2018;7.

26. Enjezab B, Farajzadegan Z, Taleghani F, et al. Health promoting behaviors in a population-based sample of middle-aged women and its relevant factors in Yazd, Iran. Int J Prev Med 2012;3(Suppl 1):S191.

27. Delshad MH, Tavafian SS, Kazemnejad A. Educational intervention for promoting stretching exercise behavior among a sample of Iranian office employees: applying the Health Promotion Model. $J$ Pain Res 2019;12:733-42.

28. Delshad MH, Tavafian SS, Kazemnejad A. Factors predicting the stretching exercise behaviors of the office employees working in the Shahid Beheshti University of Medical Sciences in Tehran, Iran. Rev Invest Clin. In Press. 2019.

29. Tavafian SS, Jamshidi AR, Mohammad K. Treatment of low back pain: randomized clinical trial comparing a multidisciplinary groupbased rehabilitation program with oral drug treatment up to 12 months. Int J Rheum Dis 2014;17:159-64. 